\title{
Dispositivos midiáticos de participação das novelas da TV Globo e a mobilização da liberdade controlada como regime interacional
}

\author{
Diego Gouveia Moreira ${ }^{1}$
}

Resumo: A televisão vem passando por grandes reconfigurações provocadas, entre outros fatores, pela cultura participativa. No Brasil, a TV Globo também se reposicionou para atrair audiência. Este artigo busca compreender como o estímulo à cultura participativa na TV Globo levou a empresa a operacionalizar a participação de sua audiência na tentativa de não perder o controle sobre as interações produzidas por ou a partir de suas telenovelas, garantindo, assim, a gerência sobre seu público. Para entender essa tensão entre participação e controle, utiliza-se o conceito de dispositivo midiático de participação. Ao final, constata-se que, uma vez instalados, esses dispositivos acionam determinados regimes de interação que configuram o que denominamos de liberdade controlada.

Palavras-chave: TV Globo, Cultura Participativa, Novela, Dispositivos midiáticos de participação, Regimes Interacionais.

\begin{abstract}
Television has undergoing major reconfigurations caused, among other factors, the participatory culture. In Brazil, TV Globo also repositioned to attract audience. This article seeks to understand how the encouragement of participatory culture on TV Globo led the company to operationalize the participation of its audience in an attempt to not lose control over the interactions produced by or from its telenovelas, thus ensuring the management about your audience. To understand this tension between participation and control, it uses the concept of media dispositives participation. In the end, it appears that, once installed, these devices trigger certain interaction schemes that in the case of the Globe, constitute what we call controlled freedom.
\end{abstract}

Keywords: TV Globo, Participatory Culture, Novela, Media Dispositives of Participation, Interactional Regime.

\section{Introdução: apresentação do contexto e do problema de pesquisa}

A cultura da convergência, marcada pelo movimento migratório dos consumidores por múltiplos suportes e mercados midiáticos em busca de novas experiências (JENKINS, 2008), alterou a forma como a TV lida com o público. Atenta, a TV, para sobreviver e atrair audiência, precisou adotar um modelo de produção transmídia, ou seja,

\footnotetext{
${ }^{1}$ Jornalista e professor doutor do Núcleo de Design do Centro Acadêmico do Agreste da Universidade Federal de Pernambuco nos cursos de Comunicação Social (com ênfase em mídias sociais e produção cultural)e Design. E-mail: dgmgouveia@gmail.com.
} 
[...] orientado pela distribuição em distintas mídias e plataformas tecnológicas de conteúdos associados entre si e cuja articulação está ancorada em estratégias e práticas interacionais propiciadas pela cultura participativa estimulada pela digitalização e convergência dos meios (FECHINE et al., 2013, p. 26).

Na TV Globo, a transmidiação se deu com o lançamento de conteúdos na internet, seja a partir de páginas criadas pela emissora ou de perfis em redes sociais e aplicativos. Os conteúdos transmídias, aqueles cuja produção de sentido está ancorada na articulação sinérgica entre diferentes mídias/plataformas e no engajamento proposto ao consumidor, coincidem com os discursos de estímulo à cultura participativa, entendida como o cenário e o conjunto variado de possibilidades abertas aos consumidores de maior acesso, produção e colocação em circulação de conteúdos midiáticos, a partir da digitalização e convergência dos meios (FECHINE et al., 2013).

Ao criar possibilidades de interação do público com os conteúdos televisivos na internet e redes sociais online, surgiu na emissora a preocupação de estimular a participação, a partir de estratégias de interação com o público na internet, sem perder o controle sobre suas produções com a criação de normas para que essa participação seja possível. Este artigo problematiza como a TV Globo operaciona a participação de sua audiência numa tentativa de não perder o controle sobre suas produções, exercendo gerência sobre seu público. Para análise desse fenômeno, foram acompanhadas, em diários analítico-descritivos telenovelas da emissora (Malhação ${ }^{2}$, Boogie Oogie ${ }^{3}$, Geração Brasil $^{4}$ e Império ${ }^{5}$ ) por serem, como afirmam o gerente de Formatos da área de Desenvolvimento Artístico e Portfólio da TV Globo, Alex Medeiros, e o autor e roteirista Gustavo Contijo, o espaço privilegiado de investimentos da emissora na interação com o público (MEDEIROS; CONTIJO, 2013, p. 349).

Nos estudos sobre poder, foi fundamental para este trabalho as ideias de Michel Foucault. Ele estabelece que o governo, em qualquer situação, é operado a partir de dispositivos, que controlam as estratégias e práticas sociais. Baseado nisso, em confluência

\footnotetext{
${ }^{2}$ Série de televisão brasileira do estilo "soap opera", voltada para o público adolescente. Produzida e exibida pela Rede Globo desde 24 de abril de 1995. A temporada analisada foi a Malhação Sonhos de 2014/2015. Considerada novela pela forma como é consumida no Brasil.

${ }^{3}$ Telenovela escrita por Rui Vilhena e exibida no horário das 18 horas desde 4 de agosto de 2014, substituindo Meu Pedacinho de Chão.

${ }^{4}$ Telenovela escrita por Filipe Miguez e Izabel de Oliveira e exibida pela Rede Globo no horário das 19 horas, entre 5 de maio e 31 de outubro de 2014, em 155 capítulos, 7 substituindo Além do Horizonte e sendo substituída por Alto Astral.

${ }^{5}$ Telenovela escrita por Aguinaldo Silva e exibida no horário das 21 horas desde 21 de julho de 2014, substituindo Em Família.
} 
com a noção de Fechine (2014a), surge a ideia de que o dispositivo midiático de participação é a forma de governo do projeto transmídia. E que esses dispositivos geram regimes de interação. A partir do modelo interacional de Landowski, é possível compreender as respostas do público diante do projeto transmídia nos espaços habilitados pela instância enunciadora, mas também nos espaços não oficiais. Observamos que existem dois eixos de interação nos espaços habilitados pelas emissora (Articulação e Atuação) e outros dois em locais não oficiais (Apropriação e Desvio). O artigo se revela importante ao investigar e nomear como liberdade controlada o regime de interação possível diante das telenovelas da TV Globo. Antes, no entanto, de aprofundar as discussões sobre os regimes interacionais, será explorado o conceito de dispositivo a partir dos estudos de Michel Foucault.

\section{A noção de dispositivo em Michel Foucault e o conceito de dispositivo midiático de participação}

Para compreender a ideia de gerência, importante para este artigo na medida em que ajuda a pensar como a TV Globo operacionaliza a participação da audiência numa tentativa de não perder o controle de suas produções, é fundamental recuperar as postulações de Michel Foucault sobre governo. Por governo, Foucault (2001) compreende iniciativas que, de alguma forma, tentam reger a população. A governamentalidade seria o conjunto de procedimentos, técnicas e métodos que garantem a condução dos homens.

A regência das atividades da população é realizada a partir da estruturação de dispositivos, ou seja, o governo é exercido a partir de dispositivos. Não se trata apenas de uma sociedade disciplinar, que buscava normalizar a sociedade, mas de uma sociedade de controle, numa relação de poder em que alguns homens são capazes de determinar a conduta de outros. Diferente da sociedade disciplinar, o controle não espera pela emergência do desvio, mas administra as várias possibilidades no sujeito. Dessa forma, criam-se dispositivos que façam sentido por si, distinguindo o que é permitido do que não é (FOUCAULT, 2001).

Em Microfísica do Poder, Foucault diz (2001):

Através deste termo tento demarcar, em primeiro lugar, um conjunto decididamente heterogêneo que engloba discursos, instituições, organizações arquitetônicas, decisões regulamentares, leis, medidas administrativas, enunciados científicos, 
proposições filosóficas, morais, filantrópicas. Em suma, o dito e o não dito são os elementos do dispositivo. O dispositivo é a rede que se pode estabelecer entre estes elementos (p. 138).

O dispositivo tem uma função estratégica. Há, em Foucault, na conceituação do termo, a ideia de que existe um fim estratégico em funcionamento como matriz de um dispositivo. As estratégias são, portanto, traçadas em função do dispositivo, que criam as condições para as estratégias.

Dois outros pesquisadores operaram com o conceito foucaultiano de dispositivo e contribuíram para discussões sobre o termo. Gilles Deleuze e Giogio Agamben trouxeram elucidações importantes para compreensão do pensamento foucaultiano. Deleuze em uma perspectiva mais ampla e Agamben cirscunscrevendo mais. A partir de análises mais amplas da obra de Michel Foucault (não se resumindo a observá-la sob o crivo do poder), Deleuze (1990), no texto, O que é um dispositivo, afirma que o dispositivo é um conceito operatório multilinear, que está alicerçado em três grandes eixos: saber, poder e subjetivação. O autor afirma que os dispositivos são máquinas de fazer ver e fazer falar.

É necessário distinguir, em todo o dispositivo, o que somos (o que não seremos mais), e aquilo que somos em devir: a parte da história e a parte do atual. A história é o arquivo, é a configuração do que somos e deixamos de ser, enquanto o atual é o esboço daquilo em que vamos nos tornando (DELEUZE, 1990, informação eletrônica).

Com Deleuze, a noção de dispositivo aproxima-se da ideia de modos de existência. "Pertencemos a certos dispositivos e neles agimos" (DELEUZE, 1990, informação eletrônica). Para Deleuze, os dispositivos engendram formas de viver. Essa noção, como veremos, aproxima-se das ideias de Agamben na compreensão sobre dispositivo.

O filósofo italiano Giorgio Agamben (2009), que se considera tributário de Michel Foucault, avaliando a importância das questões terminológicas para a filosofia, aponta o termo dispositivo como essencial para compreensão do pensamento do teórico francês. No entanto, salienta que não significa que ele teria que definir seus termos técnicos. Por isso, Agamben sistematiza e propõe uma leitura para dispositivo.

Agamben, a partir do pensamento de Foucault, descreve o dispositivo como sendo "qualquer coisa que tenha de algum modo a capacidade de capturar, orientar, determinar, interceptar, modelar, controlar e assegurar os gestos, as condutas, as opiniões e os discursos 
dos seres viventes" (p. 40). O dispositivo seria a operação por meio da qual se administra e se governa o mundo das criaturas, por isso devem sempre implicar um processo de subjetivação, isto é, devem produzir o seu sujeito (AGAMBEN, 2009).

Nesse ponto, identificamos o eixo que reúne as especificidades das definições de cada um dos autores (Foucault, Deleuze e Agamben) para o conceito de dispositivo: processo de subjetivação.

Brasil e Migliorin (2010), no artigo Biopolítica do amador: generalização de uma prática, limites de um conceito, afirmam que, na modernidade, a subjetividade "se produzia no cruzamento dos poderes normativos disseminados por todo tipo de instituição, hoje, em uma sociedade dita pós-disciplinar, ela se cria em processos de autogestão" (p. 87). Em cima dessa ideia, os pesquisadores distinguem duas etapas do capitalismo importantes para compreensão da subjetividade. De acordo com eles, no capitalismo de predominância industrial, ainda era possível separar os processos de produção (marcado pela busca por produtividade baseada no espaço e tempo do trabalho) e os de reprodução (que se voltam para o consumo, lazer e tempo livre). Já, no capitalismo avançado, considerado predominantemente cognitivo e imaterial, produção e consumo não se separam mais.

[...] trata-se de um capitalismo flexível, não hierárquico, que deve ser ágil o suficiente para perceber as mínimas mudanças no humor e no desejo dos consumidores. Ou seja, o capitalismo contemporâneo torna-se, cada vez mais intensamente, capilarizado à vida ordinária, a seus excessos e suas gratuidades ( $\mathrm{p}$. $88)$.

Nesse sentido, os autores consideram que há um deslocamento da produção de mercadorias à criação de subjetividades.

\begin{abstract}
Já não se trata mais apenas de tornar os corpos dóceis para a produção de mercadorias industrializadas e para a reprodução de uma dada ordem social, mas de fazer coincidir consumo e formas de vida [...] Se em um dado momento histórico falávamos em processos de subjetivação, para entender a constituição e processualidade do indivíduo, esse processo hoje não pode ser pensado sem que consideremos o devir-capital da vida. O indivíduo contemporâneo se engendra em um permanente processo de capitalização (p. 88-89).
\end{abstract}

É justamente na acepção de promover modos de existência e processos de subjetivação que o conceito de dispositivo se torna importante para este trabalho. Como foi visto, o 
governo é a instância maior a partir da qual existem os dispositivos que criam as estratégias e práticas necessárias para exercício da governança.

Circunscrevendo essa ideia aos conceitos trabalhados neste artigo, percebe-se que o governo da participação da audiência depende dos dispositivos criados pela mídia para exploração das estratégias e práticas de estímulo à cultura participativa. $\mathrm{O}$ dispositivo midiático de participação seria um conjunto de estratégias criadas para conduzir os consumidores à participação, que, dessa forma, promove processos de subjetivação planejados estrategicamente pela instância midiática de governo ou, como definiu Fechine (2014a, informação verbal ${ }^{6}$ ), “condições, mecanismos e procedimentos técnico-expressivos por meio dos quais se busca governar a participação".

O processo de subjetivação, promovido pelo dispositivo midiático de participação, consiste no apelo, desejo, motivação para a participação. Dessa forma, o discurso de apelo à cultura participativa depende do dispositivo midiático de participação para existir. $\mathrm{O}$ dispositivo de participação midiático na cultura da convergência é essencial dentro da ideia do projeto transmídia, porque é a partir dele que se estabelece a interação com o consumidor.

É importante lembrar que assim como os dispositivos de segurança, o de participação deixa intervir, mas também atuam com instrumentos de proibição e prescrição.

A partir desse arcabouço teórico, pode-se chegar à conclusão de que o governo em qualquer situação é operado a partir de dispositivos, que, por sua vez, controlam as estratégias e práticas sociais. Aproximando-se do objeto de estudo deste artigo, o dispositivo midiático de participação é a forma de governo do projeto transmídia, diferenciando-se da própria noção de transmidiação, visto que as estratégias são sobredeterminadas pelo dispositivo que tem o objetivo de gerir a audiência numa perspectiva da ordem do poder e do controle da instância produtora diante de um projeto transmídia.

\section{Os dispositivos midiáticos de participação na TV Globo e a mobilização dos regimes de interação}

A materialidade dos dispositivos midiáticos de participação na TV Globo está nas plataformas criadas pela emissora de estímulo à participação. Poderíamos, então, considerar ${ }^{6}$ Durante aula da disciplina Estudos de Televisão III, oferecida pela professora no Programa de Pós-graduação em Comunicação da Universidade Federal de Pernambuco, no período de agosto a novembro de 2014. 
que essa materialidade depende das tecnologias (TV, computador, laptop, tablet, smartphone) e também dos espaços configurados pela emissora para que esses discursos de estímulo à participação sejam possíveis. São os meios nos quais podem ser encontrados os discursos de estímulo à participação. Destacam-se o site da Globo, o Gshow, os sites de cada uma de suas produções, a página oficial da Rede Globo no Facebook, a página do Gshow no Facebook, as páginas oficiais dos programas da emissora no Facebook, o perfil oficial da Rede Globo no Twitter, o perfil oficial dos programas no Twitter, a conta da Rede Globo e dos programas no Instagram, os aplicativos Globo e Globo Play para sistemas operacionais de smartphones e tablets. Além disso, podem ser considerados dispositivos midiáticos de participação, os espaços criados dentro da própria emissora que de alguma forma mobilizem a interação com o telespectador.

É possível inferir que os dispositivos acabam por criar regimes de interação entre os produtores e consumidores de produtos midiáticos. As categorias dos regimes de interação que serão apresentadas mais adiante servem para compreender os processos interacionais gerados pelas estratégias adotadas na produção de conteúdos televisivos transmídias. Com isso, será indicada a forma pela qual o enunciador compreende e planeja a participação do enunciatário diante do projeto transmídia. A ideia é mostrar as formas de participação propostas pelas estratégias transmídias como interações discursivas, a partir do modelo interacional de Landowski. E não somente as respostas do consumidor diante do projeto transmídia nos espaços habilitados pela instância enunciadora, mas também nos espaços não oficiais. A própria definição de dispositivo midiático de participação dá conta de uma tensão: pretende ser uma instância de controle, mas com margem para ações que, mesmo raras, podem escapar às influências do controlador em função justamente do apelo à colaboração. Surgem como possibilidade interações a partir dos espaços criados pela emissora e também em espaços não-oficiais.

Se a missão do dispositivo midiático de participação é gerir a participação da audiência, esse governo estabelece regimes de interação. O modelo de regimes de interação que sustenta aqui nossa argumentação foi proposto pelo semioticista francês Eric Landowski. Entrar no campo da semiótica, depois de tratar de questões de poder à luz das ideias de Michel Foucault, parece um pouco estranho inicialmente, mas um olhar atento sobre o trabalho desenvolvido por ambos pesquisadores nos mostra que estão entre as preocupações 
deles as relações de poder ou, mais especificamente no caso de Landowski, as relações de controle e risco dele decorrentes.

Landowski estimulou essa perspectiva quando, diante do nível narrativo, pensou a construção do sentido como um processo interacional entre sujeitos. São quatro os regimes de interação propostos por Landowski (2014): programação, manipulação, ajustamento e acidente (ou assentimento).

O regime da Programação é aquele em que há, como o próprio nome sugere, uma ação ou comportamento programados, muito bem determinados. Estamos diante de um regime interacional na qual o sujeito, reduzido a um único papel temático, "segue as instruções".

A Manipulação é aquele regime que está fundado sob um princípio de intencionalidade no qual se impõem as motivações e as razões do sujeito. A estratégia aqui é fortemente persuasiva. O produtor precisa até se comprometer em retribuir o sujeito manipulado conforme aceite ou recuse agir segundo a vontade da instância de produção (LANDOWSKI, 2014).

O regime do Ajustamento se dá, justamente, quando o enunciatário compartilha o sentido proposto pelo enunciador. $\mathrm{O}$ ajustamento não consiste em adaptar-se unilateralmente a um outro ator, nem em levar esse outro a submeter-se ao primeiro (LANDOWSKI, 2014).

O ajustamento comporta, porém, aspectos comuns com a sintaxe da manipulação. Ambos supõe que o parceiro com o qual se interage e com que, no caso, tenta ajustar-se, seja tratado como um actante sujeito de pleno direito, e não como uma coisa de comportamento estritamente programado (p. 49).

Landowski (2014) nos diz que a interação se assentará sobre o fazer sentir, não mais sobre a persuasão, entre inteligências, mas sobre o contágio:

[...] fazer sentir que se deseja para fazer desejar, deixar ver seu próprio medo e, por esse fato mesmo, amedrontar, causar náusea vomitando, acalmar o outro com sua própria calma, impulsionar - sem empurrar! - só por seu próprio ímpeto (p. 51).

O Acidente é um processo interativo fundado sob o princípio da probabilidade, da imprevisibilidade, da aleatoriedade. Diferentemente do que acontece no regime da programação no qual a enunciação é bem ordenada uma vez que os comportamentos são prefixados, os papéis predeterminados, no acidente, há sempre o efeito do cruzamento de duas 
trajetórias no qual não se pode identificar nem causa (regularidade) nem finalidade (intencionalidade). O Acidente acontece fora dos espaços habilitados pela instância produtora e ocorre quando o consumidor subverte o sentido proposto pelo enunciador.

Essas formas de interações propostas por Landowski configuram os modos de participação do projeto transmídia (FECHINE, 2014b). A autora afirma que existem apenas dois regimes de interação, propostos por Landowski, por meio dos quais o projeto transmídia realiza-se (atualiza-se): programação e manipulação. Ela diz isso porque ambos "pressupõem a aceitação pelo enunciatário-destinatário do trabalho de finalização da textualidade pressuposto nas estratégias do enunciador-destinador" (p. 126).

A produtividade das ideais de Landowski (2014) para compreensão do nosso objeto de estudo se dá justamente porque o seu modelo interacional permite tratar dentro do mesmo esquema explicativo o que é parte do projeto e o que não é parte do projeto, mas é um elemento constituinte dele. Ele, com os regimes de Ajustamento e Acidente, explica o que está fora dos espaços de controle, mas que precisa ser controlado. Por isso, para compreender as estratégias, precisamos também observar os Ajustamentos e Acidentes, visto que eles fazem parte do que, para instância enunciadora, precisa ser controlado.

\section{A Articulação}

Segundo Fechine (2014b), na interação discursiva da Programação, que a pesquisadora chama, para fins de análise dos regimes de interação nos projetos transmídias, de Articulação, percebe-se obediência do enunciatário às ordens dadas pelo enunciador como parte de sua estratégia de "articulação" entre mídias e plataformas. Dessa forma, o enunciatário age conforme o programa de comportamento previsto no projeto. Isso acontece quando o enunciatário acompanha o programa na televisão e consome outras informações sobre aquele produto em outros locais.

Cumpre, em outras palavras, o "roteiro", o percurso ou a "navegação" entre mídias e plataformas ambicionadas pela produção. O "trabalho de finalização" da textualização exigido do destinatário envolve, nesse caso, tão somente uma reoperação do sentido a partir da articulação com o texto de referência exibido na televisão dos conteúdos associados e complementares ofertados, geralmente, por meio de sites oficiais e aplicativos institucionais disponibilizados para dispositivos móveis, como celulares e tablets (p. 127). 
É exatamente o que acontece quando o enunciatário busca informações sobre o programa em outros lugares. Nesse modo de interação, o consumidor limita-se a "atualizar" o texto transmídia, juntar peças. Talvez esse seja o modo de interação mais servil, visto que o consumidor apenas navega pelas possibilidades estabelecidas pela instância produtora. É a condição mínima para que haja a manifestação e consumo transmídia. Fica evidente que o processo se dá a partir da navegação para outras plataformas e conteúdos oferecidos pelo programa para os enunciatários. Quando, por exemplo, o telespectador da novela Império buscava outras informações no site da novela, na fanpage no Facebook. Em uma publicação, no site de Malhação, há chamada para uma cena que irá ao ar nos próximos dias. O consumidor poderá ver a participação do bailarino Fly em Malhação, além de já saber que Jade ficará de fora da seleção. A única interação possível com o consumidor é fazer com ele acesse a notícia e leia mais ou veja o vídeo com a antecipação da cena. A TV Globo consegue manter o consumidor atento às publicações no site para que ele acesse, em primeira mão, trechos da trama que ainda não foram ao ar e, ainda por cima, atrai o público para acompanhar o capítulo na TV.

\section{A Atuação}

O regime da Manipulação, que chamaremos de Atuação em consonância com os regimes de interação possíveis a partir dos dispositivos midiáticos de participação, não se limita à articulação dos conteúdos ofertados pelo enunciador.

\footnotetext{
Nesse caso, o esforço do enunciador-destinador é para influenciar as vontades e condutas do enunciatário-destinatário, motivando-o à ação proposta. Trata-se, portanto, de um tipo de interação orientada pela intencionalidade do enunciadordestinador e pelo convencimento do enunciatário-destinatário de modo a garantir uma "resposta" esperada ao apelo à participação [...] Esse tipo de interação manipulatória exige, em suma, uma "atuação" do enunciatário-destinatário a partir da qual o texto transmídia realiza-se em meio a uma enunciação que este reconstrói o sentido proposto pelo enunciador-destinatário (FECHINE, 2014b, p. 128).
}

Ocorre quando o destinatário produz um conteúdo a partir de um conteúdo maior oferecido pelos produtores. Como exemplo, em Malhação, com o selo "Participa Aê!" e “Opina Aê", os consumidores são convocados a darem sua opinião em enquetes, apostas. No entanto, são dadas normalmente duas opções para o consumidor escolher. Os usuários 
poderiam responder clicando no "sim" ou no "não" para Marcelo contar ou não tudo (sobre a traição) para Delma. Quando a página foi consultada, o "sim” estava ganhando. É interessante observar que, na novela, o personagem acabou contando a verdade a mulher, coincidindo com o resultado da enquete reforçando o efeito de intervenção dos espectadores sobre a trama ainda que se tenha como saber pelo tipo de observação realizada se e como ocorreu esse jogo de influência recíproca. $\mathrm{O}$ fato é que, diante da emergência da cultura participativa, a emissora se vê com a demanda de estimular a interação com o consumidor. No entanto, nos espaços citados anteriormente, são oferecidas respostas ao público. O que resta a ele é clicar em uma das respostas, mas diferente da Articulação, na Atuação, o consumidor precisa estar motivado a participar e ele é recompensado pela participação, ganhando pontos, por exemplo, em uma gincana online.

\section{O desvio}

Se, na Atuação, temos a interação do consumidor com a estratégia transmídia nos espaços habilitados pela instância de enunciação, há também a possibilidade de se relacionar com esse texto transmídia fora dos espaços indicados pelo enunciador, nos espaços não habilitados. Quando isso acontece, o consumidor pode subverter o sentido proposto pelo enunciador ou compartilhar esse sentido. Fechine (2014b) nos lembra dos conteúdos que são produzidos pelos consumidores a partir de um texto transmídia e que circulam fora dos espaços habilitados pela instância produtora.

Os conteúdos não autorizados podem ser dissonantes ou consonantes com o projeto transmídia. Quando subverte o sentido do texto transmídia está associado ao regime do Acidente, que neste trabalho, para fins de aproximação com o universo de interação transmídia, estamos chamando de Desvio.

Chamou bastante atenção a forma como a TV Globo lidou, inicialmente, com as participações inusitadas por parte da audiência. Em 2011, foi criado o site Ego Estagiário. Nele, os consumidores podiam acompanhar publicações ironizando postagens do site Ego, portal de notícias sobre celebridades da Rede Globo. A chamada do site revela adequadamente o seu propósito: Famosos do jeito que você nunca viu. $\mathrm{O}$ que a equipe responsável pelo Ego Estagiário faz é recriar situações para as fotografias publicadas no Ego. 
Hoje, as publicações são permitidas pela Rede Globo, mas, em 2012, um ano depois da criação do Ego Estagiário, a emissora recomendou que o site fosse tirado do ar. Em uma publicação, no dia 7 de maio de 2012, o Ego Estagiário, que contava com cerca de 20 mil acessos diários, postou uma nota na homepage com o termo censura na parte superior. No texto, os responsáveis pelo site diziam que receberam um email da emissora quatro dias antes e que foram impedidos de manter a página no ar por violação de direitos autorais e propriedade industrial. Segundo Ego Estagiário, a Globo afirmava que o site queria se promover em cima da marca do portal Ego. A orientação era cessar imediatamente as publicações.

No final do texto, Ego Estagiário se defende mostrando que se trata de um site de paródia e por isso fazem uso das imagens e características do portal Ego. Eles incentivam que os fãs do site usem a hashtag \#GloboLiberaoEstagiario nas redes sociais.

Acompanhando a disposição dos fãs nas redes sociais para que a Rede Globo liberasse o Ego Estagiário, o portal de paródias postou textos pedindo a autorização para manter o site.

Brincando com uma frase, supostamente dita pela celebridade Mulher Melancia, a equipe do Ego Estagiário diz que "Nada é impossível". O movimento para que a Globo permitisse a continuação das atividades do site foi bastante intenso.

Por fim, doze dias depois da interdição, a Globo autorizou que o site continuasse com as paródias.

No post, a equipe retoma o uso do termo "censura" e avisa aos leitores que, depois da ajuda de todos com o uso da tag \#GloboLiberaoEstagiario, a Rede Globo emitiu permissão concordando com a manutenção da paródia Ego Estagiário desde que de forma independente.

Como evidência de que existem desvios e que a emissora monitora para se prevenir, a Rede Globo criou, para gerir de forma mais clara os perfis oficiais e os fakes, a página "alerta redes sociais" dentro do site institucional da emissora. Nele, são divulgadas notícias sobre perfis falsos de atores, apresentadores e programas da empresa. Como veremos na figura a seguir, as notícias trazem os nomes dos atores, apresentadores e programas que tiveram perfis criados por consumidores da internet para que as pessoas saibam que não se tratam de fontes oficiais.

Percebe-se que há uma notícia, publicada em outubro, falando sobre um perfil criado com o nome da atriz Renata Sorrah em uma rede social que não é o da atriz. De acordo com o 
alerta, a global não mantém contas em nenhuma rede online. Em junho de 2014, foi publicada uma informação relativa à Boogie Oogie. Nela, a Rede Globo esclarece que não criou a página da novela.

\title{
A Apropriação
}

Além dos conteúdos desviantes, circulam, por espaços não oficiais, textos que podem estar alinhados ao projeto transmídia. O consumidor acaba sendo contagiado pelo discurso do produtor e se apropria desse discurso como se fosse a própria instância enunciadora. Quando isso é observado, aproxima-se do regime de interação do ajustamento, que chamaremos de apropriação.

\begin{abstract}
A produção desse tipo de conteúdo pressupõe, no entanto, um enunciatáriodestinatário motivado pelo enunciador-destinador, o que nos levaria a indagar se esse tipo de interação não teria igualmente uma natureza manipulatória. Essa motivação é, de fato, o resultado de estratégias que, mesmo quando não demandam do enunciatário-destinatário uma performance direta, buscam de algum modo envolvê-lo, apelando para uma manipulação prévia por meio da qual o enunciadordestinador produz um fazer-gostar ou um cultivo do gosto (p. 130).
\end{abstract}

Um exemplo do Apropriação são os diversos Tumblrs que tratavam de Malhação Sonhos. Os criadores dos Tumblr repercutiam imagens de cenas de personagens que gostavam em Malhação. Entre eles: Tea Malhação; Bellavitti; Humbelle e Perina; Malhação Online; True Love Brunah; Perina Sonhos; Perina Icons; Team Perina.

Os conteúdos dos tumblers são muito parecidos. São postadas, pelos proprietários, imagens de cenas e personagens de Malhação. Muitos Tumblers como Humbelle e Perina se dedicam a casais da série. 


\section{Liberdade controlada como regime interacional possível dos dispositivos midiáticos de participação das telenovelas da TV Globo}

É importante ressaltar que os regimes não são estanques. Para haver atuação, é preciso ter tido articulação, por exemplo. A articulação pode vir depois de um desvio ou apropriação. A rede dinâmica de interações discursivas, situada entre a prudência e a aventura, nos leva a pensar em duas possíveis engrenagens acionadas durante a interação do enunciatário diante dos enunciados propostos pelas instâncias produtoras: controle e liberdade. O movimento é feito, neste artigo, para aproximar ainda mais os regimes de interação da perspectiva foucaultiana de governo a partir de dispositivos. No caso deste trabalho, a gestão da audiência feita a partir de dispositivos midiáticos de participação.

Dentro desse processo de influência recíproca no qual as posições dos regimes de interação não são estanques e das possibilidades de aventura e prudência na enunciação, podese chegar a uma adaptação dos termos para liberdade e controle, respectivamente. No quadro a seguir, deixamos mais claro como a ideia de liberdade controlada é alimentada pelos dispositivos midiáticos de participação a partir dos regimes de interação. A ideia de liberdade controlada só se constrói a partir das quatro posições do regime interacional. A liberdade controlada não estaria em nenhum dos lados. A liberdade controlada seria a forma de governo da Globo sobre o universo interacional, envolvendo, dessa forma, as quatro possibilidades criadas pelo projeto transmídia. Afinal, a vigilância, como é descrita, é sobre todo o universo interacional. O monitoramento não se limita aos espaços institucionais. Nesse caso, em cada lado do quadrado o que temos são modos de participação: no esquerdo, uma "participação autorizada" e no outro uma "participação não autorizada" (ou desautorizada). 
Quadro 1 - Liberdade controlada oferecida pelos dispositivos midiáticos de participação a partir dos regimes de interação

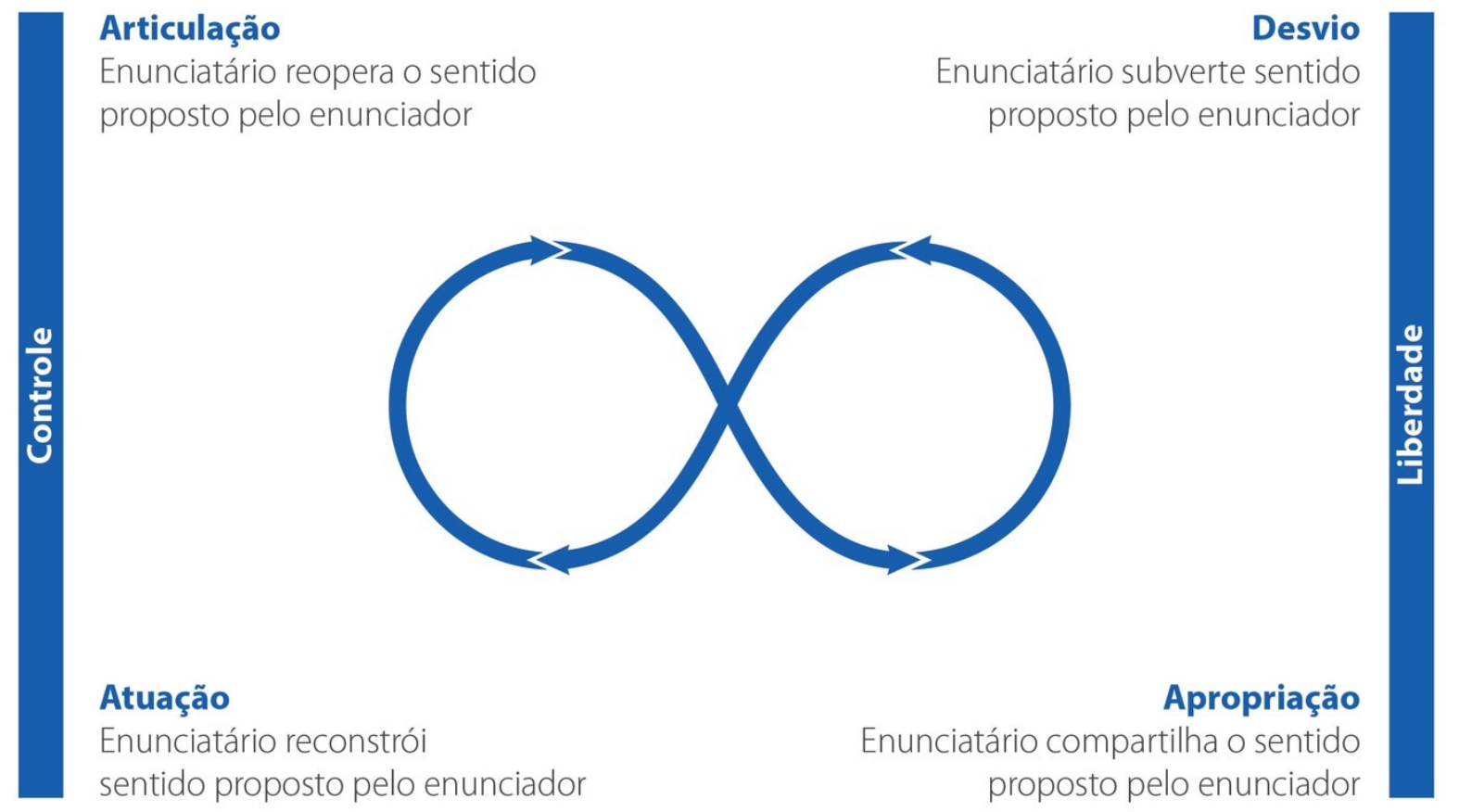

Fonte: $\mathrm{O}$ autor

\section{Considerações finais}

Nos regimes de interação, o controle é maior nos regimes da Articulação e Atuação. Neles, o consumidor tem a liberdade de decidir interagir ou não. No entanto, quando o contrato é firmado, a audiência precisa estar disposta a assumir determinados tipos de comportamento que atendam aos requisitos da interação. Nos regimes de interação em que o controle é teoricamente menor (Apropriação e Desvio), a vigilância da TV Globo se faz presente. Qualquer atitude que contrarie os interesses da emissora pode fazer com que a empresa acione medidas da legislação para contornar a situação e preservar comportamentos que considera adequados.

Embora não divulgue os resultados, porque faz parte dos interesses da emissora, a Rede Globo certamente, assim como grandes conglomerados midiáticos realiza 
monitoramento de mídias sociais online. Esse recurso faz monitoramento de dados em redes sociais - como o Twitter e o Facebook - com o auxílio de softwares de busca de menções online. Expressões e vocábulos da língua portuguesa referente aos objetos de pesquisa são relacionados e classificados com a utilização de técnicas de análise textual, de forma a restringir as menções à área do tema de interesse. Dessa forma, consegue-se conhecer melhor o comportamento dos consumidores diante dos produtos da TV Globo e gerir melhor a oferta de conteúdos para a audiência tanto na televisão quanto na internet.

Assim, todo processo interacional das telenovelas, possibilitados a partir dos dispositivos midiáticos de participação, está submetido à ordem do que consideramos como uma "liberdade controlada", aquele tipo de conduta na qual se faculta ao indivíduo a capacidade de agir por vontade própria (sem obrigatoriedade ou coerções), mas dentro de condições bem tuteladas.

\section{Referências}

AGAMBEN, Giorgio. O que é o contemporâneo? e outros ensaios. Chapecó: Argos, 2009. $92 \mathrm{p}$.

BRASIL, André; MIGLIORIN, Cézar. Biopolítica do amar: generalização de uma prática, limites de um conceito. Galáxia, São Paulo, n. 20, p. 84-94, dez. 2010. Disponível em: $<$ http://revistas.pucsp.br/index.php/galaxia/article/viewFile/3280/3292>. Acesso em: 20 jan. 2015 .

DELEUZE, Gilles. ¿Que és un dispositivo? In: DELEUZE, Gilles. Michel Foucault, filósofo. Barcelona: Gedisa, 1990. p. 155-161.

FECHINE, Yvana; GOUVEIA, Diego; ALMEIDA, Cecilia; COSTA, Marcela; ESTEVÃO, Flávia. Como pensar os conteúdos transmídias na teledramaturgia brasileira? Uma proposta de abordagem a partir das telenovelas da Globo. In: LOPES, Maria Immacolata Vassallo de (org.). Estratégias de Transmidiação na Ficção Televisiva Brasileira. Porto Alegre: Sulina, 2013. p. 19-60.

FECHINE, Yvana. Estudos de TV III. Recife, Universidade Federal de Pernambuco, 20 out. 2014a. Anotação de aula.

. Interações discursivas nas manifestações transmídias. In: FECHINE, Yvana et al. (orgs.). Semiótica nas práticas sociais. São Paulo: Estação das Letras e Cores, 2014b. p. 117133. 
FOUCAULT, Michel. Microfísica do Poder. 16. ed. Rio de Janeiro: Graal, 2001.

. Segurança, Território e População. São Paulo: Martins Fontes, 2008. 572 p.

JENKINS, Henry. Cultura da Convergência. São Paulo: Aleph, 2008. 428p.

LANDOWSKI, Eric. Interações Arriscadas. São Paulo: Estação das Letras e Cores, 2014.

MEDEIROS, Alex; CONTIJO, Gustavo. Transmídia por quem faz: ações na teledramaturgia da Globo. In: LOPES, Maria Immacolata Vassalo de (org.). Estratégias de transmidiação na ficção televisiva brasileira. Porto Alegre: Sulina, 2013. p. 345-355. 